\title{
Moisture in thermal zones - a dynamic modelling approach
}

\author{
Martin Kremer ${ }^{\mathrm{a}}$, Paul Mathis ${ }^{\mathrm{a}}$, Dirk Müller ${ }^{\mathrm{a}}$ \\ ${ }^{a}$ RWTH Aachen Unitverstity, Institute for Energy Efficient Buildings and Indoor Climat, Aachen, Germany
}

\begin{abstract}
Healthy and comfort indoor air becomes more relevant for the persons working or living in buildings. Keeping the indoor air temperature in a comfortable range is common for room air conditioning. Nevertheless, keeping the moisture in a comfortable range is often neglected, as the influence of too dry or too humid air on health is underestimated. To predict the moisture content in indoor air environments over yearly periods, we enhanced a dynamic building model with a moisture balance. Using this model, we analyzed the influence of moisture recovery systems in residential ventilation on the indoor air humidity compared to heat recovery systems. The comparison shows that moisture recovery systems significantly decrease the number of hours of dry air during a yearly period.
\end{abstract}

Peer-review under the responsibility of the organizing committee of the ICMB21.

Keywords: moisture balance; indoor air humidity; moisture recovery

\begin{tabular}{|llllll|}
\hline \multicolumn{2}{ll}{ Nomenclature } & & & & \\
$\dot{m}$ & Mass flow rate $(\mathrm{kg} / \mathrm{s})$ & $\dot{Q}$ & Heat flow rate $(\mathrm{W})$ & $\rho$ & Density $\left(\mathrm{kg} / \mathrm{m}^{3}\right)$ \\
$M$ & Activity degree $(\mathrm{met})$ & $A C R$ & Air exchange rate $(1 / \mathrm{h})$ & $X$ & absolute humidity $(\mathrm{kg} / \mathrm{kg})$ \\
$A$ & Body area $\left(\mathrm{m}^{2}\right)$ & $V$ & Volume $\left(\mathrm{m}^{3}\right)$ & $t$ & Time $(\mathrm{s})$ \\
$\mathrm{HRS}$ & Heat recovery system & MRS & Moisture recovery system & & \\
\end{tabular}

\section{Introduction/Background}

Maintaining the thermal comfort in buildings is the task of Heating, Ventilation and Air Conditioning systems. Next to heating and cooling processes the air humidification and dehumidification is necessary to provide comfortable air conditions in indoor spaces. As these processes are energy intensive, most residential ventilation units are not equipped with components to treat humidity. Nevertheless, regarding comfort and health, a moderate indoor air humidity between 30 and $65 \%$ is recommended [14]. Instead of installing humidification, moisture recovery systems (MRSs) can be used to humidify the outdoor air for cold and dry climates and keep a comfortable range in the indoor air environment. To predict the internal loads and moisture content in the building, we enhanced an existing dynamic model for thermal zones [5, 6] by adding a moisture balance. This paper examines the effect of MRSs in residential ventilation units compared to common heat recovery systems (HRSs) using the enhanced thermal zone model. This effect has been examined in field tests beforehand [7].

\section{Mass balance for moisture in buildings}

Figure 1 shows the structure of the mass balance in the thermal zone model. The room air volume is assumed to be ideally mixed within the thermal zone. According to SIA 2024 [8], the internal gains in residential buildings can be divided into moisture gains by the occupants and moisture gains by plants, etc. The moisture produced by one person is defined by equation (1) [8].

$$
\dot{m}_{\text {moisture,person }}=\frac{1}{2520} \frac{\mathrm{kg}}{\mathrm{s}} \cdot\left(M \cdot 58 \frac{\mathrm{W}}{\mathrm{m}^{2}} \cdot A_{\text {person }}-\dot{Q}_{\text {person }}\right) \cdot 10^{-3}
$$

The mass flow rate of moisture by one person $\dot{m}_{\text {moisture,person }}$ is influenced by the activity degree $M$ (1.2 met according to [8]), the body surface $A_{\text {person }}$ of a person (1.8 $\mathrm{m}^{2}$ according to [8]) and the temperature dependent heat production $\dot{Q}_{p e r s o n}$ of a person [8]. We assume the moisture produced by occupants to be in gaseous state. By multiplying the mass flow rate with the specific heat of vaporization at the average body temperature of $37^{\circ} \mathrm{C}(2413 \mathrm{~kJ} / \mathrm{kg})$, the latent heat is added to the air volume. By scaling the mass flow rate produced by one person with the statistical number of persons in a residential building (one person per $50 \mathrm{~m}^{2}$ ) according to [8]) the total moisture and latent heat production of the occupants is derived.

The moisture production of plants, etc. is provided by SIA 2024 as a specific value. For residential buildings this value is $0.5 \mathrm{~g} /\left(\mathrm{h} \mathrm{m}^{2}\right)$. In analogy to the moisture production of the occupants, the moisture gains of plants, etc. are assumed to be in gaseous state. The heat of vaporization $(2453 \mathrm{~kJ} / \mathrm{kg})$ at room temperature is added to the air volume.

The third influence factor on the indoor air humidity is ventilation and infiltration. The moisture exchange rate $\dot{m}_{\text {moisture,exchange }}$ between the thermal zone and the outdoor air by infiltration is expressed by equation (2). 
ICMB21

$$
\dot{m}_{\text {moisture }, \text { exchange }}=\frac{A C R}{3600 \mathrm{~s} / \mathrm{h}} \cdot V_{\text {air }, \text { room }} \cdot \rho_{\text {air }} \cdot\left(X_{\text {indoor }}-X_{\text {outdoor }}\right)
$$

The moisture exchange rate is modelled by the air exchange rate $A C R$ and the difference between the indoor air humidity $X_{\text {indoor }}$ and the outdoor air humidity $X_{\text {outdoor }}$, considering the room air volume $V_{\text {air,room }}$ and the indoor air density $\rho_{\text {air }}$. The moisture exchange rate by ventilation is calculated analogously substituting the outdoor air humidity with the supply air humidity. The change of the indoor air humidity can be expressed by the sum of all mass flow rates of moisture divided by the mass of the air in the room volume (equation (3)). Moisture storage in walls is neglected.

$$
\frac{d X_{\text {indoor }}}{d t}=\frac{\sum \dot{m}_{\text {moisture }, i}}{m_{\text {air }}}
$$

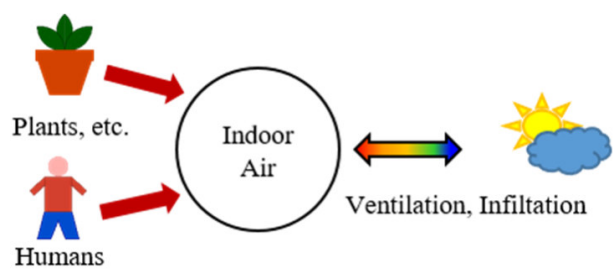

Figure 1. Mass balance for the moisture content in a thermal zone

\section{Influence of moisture recovery systems in residential ventilation on the indoor air humidity compared to heat recovery systems}

Using the enhanced thermal zone model, we analyzed the influence of MRSs in residential ventilation units on the indoor air humidity compared to heat recovery systems. We parametrized a residential building consisting of one thermal zone with a net floor area of $140 \mathrm{~m}^{2}$. For the building parameters, we used an archetype model generated with the tool TEASER [9] for 2015 as the year of construction and the tabula method [9]. As a reference, we used a common residential ventilation unit consisting of a HRS, an electrical pre-heater for frost protection and two fans and compared it with a MRS as a retrofitting method in hourly resolved simulation studies.

Table 1 shows the hours over a total year of operation, where the humidity lies below $30 \%$ and above $65 \%$ relative humidity. It becomes clear that MRSs are able to prevent the indoor air falling below the critical lower limit of $30 \%$ for most of the year. This leads to an improvement of thermal comfort and a more healthy indoor air environment.

Table 1. Hours of operation exceeding comfortable ranges of humidity.

\begin{tabular}{|l|l|l|}
\hline Recovery System & $<30 \% \mathrm{rH}$ & $>65 \% \mathrm{rH}$ \\
\hline Heat Recovery & $1244 \mathrm{~h} / \mathrm{a}$ & $0 \mathrm{~h} / \mathrm{a}$ \\
\hline Moisture Recovery & $223 \mathrm{~h} / \mathrm{a}$ & $0 \mathrm{~h} / \mathrm{a}$ \\
\hline
\end{tabular}

\section{Conclusion and outlook}

In this paper, we have introduced an enhanced dynamic model of a thermal zone including a moisture balance by which we have analysed the effect of MRSs in residential ventilation units on the comfort in the room. The analysis shows that moisture recovery systems can reduce the hours of discomfort regarding indoor air humidity in a moderate climate significantly. Hence, MRSs can help to provide healthier and more comfortable indoor air conditions without energy intensive humidification processes. This correlates with the results of the field study executed beforehand [7].

\section{References}

[1] Rief, S., Jurecic, M. (2014). Air humidity at the office workplace. Stuttgart.

[2] Abusharha, A. A., Pearce, E. I. (2013). The effect of low humidiy on the human tear film. Cornea, 32, 429-434.

[3] Arundel, A.V., et. Al. (1986). Indirect health effects of relative humidity in indoor environments. Environmental health perspectives, 65. $351-361$.

[4] Dietz, et. Al. (2020). 2019 Novel Coronavirus (COVID-19) Pandemic: Built Environment Considerations To Reduce Transmission. American Society for Microbiology Journals.

[5] Lauster, M. et. Al. (2014). Low order thermal network models for dynamic simulations of buildings on city district scale. Building and Environment, 73. 223-231

[6] Müller, D. et. Al. (2016). AixLib - An Open-Source Modelica Library within the IEA-EBC Annex 60 Framework. Proceedings In BauSim 2016. Dresden, Germany. 3-9

[7] Frei, B. (2007). Field Comparison of Heat and Enthalpy Exchangers in Compact Ventilation Units. Swiss Federal Office of Energy. (Final report)

[8] SIA 2024 (2015). Room usage data for energy and building sevices engineering. Zürich. Switzerland.

[9] Remmen, P. et. Al. (2017). TEASER: an open tool for urban energy modelling of building stocks. Journal of Building Performance Simulation. 